Cronfa - Swansea University Open Access Repository

This is an author produced version of a paper published in :

Medical Physics

Cronfa URL for this paper:

http://cronfa.swan.ac.uk/Record/cronfa20153

\title{
Paper:
}

Al-Affan, I., Hugtenburg, R., Bari, D., Al-Saleh, W., Piliero, M., Evans, S., Al-Hasan, M., Al-Zughul, B., Al-Kharouf, S. \& Ghaith, A. (2015). Dose reduction of scattered photons from concrete walls lined with lead: Implications for improvement in design of megavoltage radiation therapy facility mazes. Medical Physics, 42(2), 606-614.

http://dx.doi.org/10.1118/1.4905100

This article is brought to you by Swansea University. Any person downloading material is agreeing to abide by the terms of the repository licence. Authors are personally responsible for adhering to publisher restrictions or conditions. When uploading content they are required to comply with their publisher agreement and the SHERPA RoMEO database to judge whether or not it is copyright safe to add this version of the paper to this repository. http://www.swansea.ac.uk/iss/researchsupport/cronfa-support/ 


\section{Dose reduction of scattered photons from concrete walls lined with lead: implications for improvement in design of megavoltage radiation therapy facility mazes}

I.A.M. Al-Affan ${ }^{\mathrm{a}}$, R. P. Hugtenburg ${ }^{\mathrm{a}}$, D.S. Bari ${ }^{\mathrm{a}, \mathrm{g}}$, W. M. Al-Saleh ${ }^{\mathrm{a}, \mathrm{f}}$, M. Piliero ${ }^{\mathrm{a}}$, S. Evans $^{\mathrm{b}}$, M. Al-Hasan ${ }^{\mathrm{c}}$, B. Al-Zughul ${ }^{\mathrm{c}}$, S. Al-Kharouf ${ }^{\mathrm{d}}$ and A. Ghaith ${ }^{\mathrm{e}}$,

10 a Swansea University, Swansea SA2 8PP, UK

bepartment of Medical Physics and Clinical Engineering, Singleton Hospital, Swansea, SA2 8QA, UK

${ }^{\mathrm{c}}$ College of Sciences, Zarqa University, Zarqa, Jordan

${ }^{\mathrm{d}}$ The Royal Scientific Society, Amman, Jordan.

$15{ }^{\mathrm{e}}$ Association of Arab Universities, Amman, Jordan

${ }^{\mathrm{f}}$ King Saud Bin Abdulaziz University for Health Science, Hofuf, Kingdom of Saudi Arabia.

${ }^{\mathrm{g}}$ University of Zakho, Duhok, Iraq.

20 Key words:

Dose. Radiotherapy. Lead on Maze walls 


\section{ABSTRACT}

PURPOSE: This study explores the possibility of using lead to cover part of the radiation therapy facility maze walls in order to absorb low energy photons and reduce the total dose at the maze entrance of radiation therapy rooms.

METHODS: Experiments and Monte Carlo simulations were utilized to establish the possibility of using high- $Z$ materials to cover the concrete walls of the maze in order to reduce the dose of the scattered photons at the maze entrance. The dose of the backscattered photons from a concrete wall was measured for various scattering angles. The dose was also calculated by the FLUKA and EGSnrc Monte Carlo Codes. The FLUKA Code was also used to simulate an existing radiotherapy room to study the effect of multiple scattering when adding lead to cover the concrete walls of the maze. Monoenergetic photons were used to represent the main components of the $\mathrm{x}$-ray spectrum up to $10 \mathrm{MV}$.

RESULTS: It was observed that when the concrete wall was covered with just $2 \mathrm{~mm}$ of lead the measured dose rate at all backscattering angles was reduced by $20 \%$ for photons of energy comparable to Co-60 emissions and $70 \%$ for Cs-137 emissions. The simulations with FLUKA and EGS showed that the reduction in the dose was potentially

40 even higher when lead was added. One explanation for the reduction is the increased absorption of backscattered photons due to the photoelectric interaction in lead. The results also showed that adding $2 \mathrm{~mm}$ lead to the concrete walls and floor of the maze reduced the dose at the maze entrance by up to $90 \%$. 
45 CONCLUSIONS: This novel proposal of covering part or the entire maze walls with a few millimeters of lead would have a direct implication for the design of radiation therapy facilities and would assist in upgrading the design of some mazes, especially those in facilities with limited space where the maze length cannot be extended to sufficiently reduce the dose. 


\section{INTRODUCTION}

In radiation therapy $(\mathrm{RT})$ rooms, the length and shape of the maze play an important role in reducing the radiation dose at the maze entrance (radiation exit). Previously, steps

55 taken were to use a door at the maze entrance, to extend the maze length in order to achieve the required reduction in dose, or to add a turn with a small length in the maze (called a leg) in a different direction. In addition, nibs, baffles and lintels are often used to reduce the dose rate of the photons emerging from the RT rooms.

60 Using a door or extending the length of the maze, whether in one direction or adding another leg in a different direction, would add to the building cost of RT rooms and also occupy more space, which may be a significant issue when an existing RT room is to be upgraded within an area of very limited space.

65 A few studies have shown the level of dose due to scattered photons at the maze entrance and also the characteristics of the photon energy due to scattering in the patient, collimators and walls, and leakage from the accelerator head. ${ }^{1,2,3}$ Photons reaching the maze entrance may be divided into two groups; photons that are generated from primary beam scattering and photons that penetrate the machine head (leakage). 
Photons that are generated from the primary beam scattering off collimators, the patient, leakage and air in the room undergo a multiple scattering process through the maze itself. The energy spectra of these photons are found not to exceed $400 \mathrm{keV}$ with an average of about $100 \mathrm{keV} .{ }^{2,3,4}$ The dose at the maze entrance from this group of photons depends on the maze length, number of turns (legs), area of the maze opening and the reflection coefficient of materials in the maze walls.

Leakage photons travel directly through the wall adjacent to the maze entrance. The energy distribution of these photons may range from below $100 \mathrm{keV}$ to a value almost approaching the maximum value in the primary beam. ${ }^{2}$ The dose at the maze entrance 80 from this group will depend on the energy spectrum of the leakage radiation, the thickness, elemental composition and density of the concrete wall.

In this study, the aim was to focus on the first group (scattered radiation) which is more difficult to predict, yet can contribute more than $50 \%$ of the dose at the maze entrance. ${ }^{2,3}$

As mentioned above, some fraction of photons or photon dose reaching the maze entrance is from scattered photons. The energy spectra of these photons were calculated by $\mathrm{Al}-\mathrm{Affan}^{3}$ who showed that there were photons below $200 \mathrm{keV}$ as well as higher energy components between 200 and $400 \mathrm{keV}$. On impact with the maze walls, floor and 90 ceiling, these photons scatter at various depths in the concrete. The energy distribution of these photons will follow the Compton scattering equation, which depends on the incident energy of the photon, the backscattering angle and the material type, i.e. electron density. The maximum energy of these backscattered photons is less than $0.4 \mathrm{MeV}$ for 
Co-60 and Cs-137 gamma sources. For photons generated from a high energy Linear

95 Accelerator the maximum energy of backscattered photons approaches $0.511 \mathrm{MeV}$.

When these photons are backscattered $\left(90^{\circ}-150^{\circ}\right.$, see Fig. 1a) they experience further scattering in all directions in the concrete wall, with many photons being absorbed due to the photoelectric effect. The degree of absorption for the photoelectric effect is

100 proportional to $Z^{3}$ for the high atomic number constituents in the wall material. For example, when a thin sheet of lead $(\mathrm{Z}=82)$ is placed in front of the concrete wall (average $Z=14$ ) the ratio of photoelectric effect will be about 200 times more efficient in absorbing the backscattered photons through the photoelectric process than the concrete wall alone, although the lead itself would contribute to the photon backscattering. 

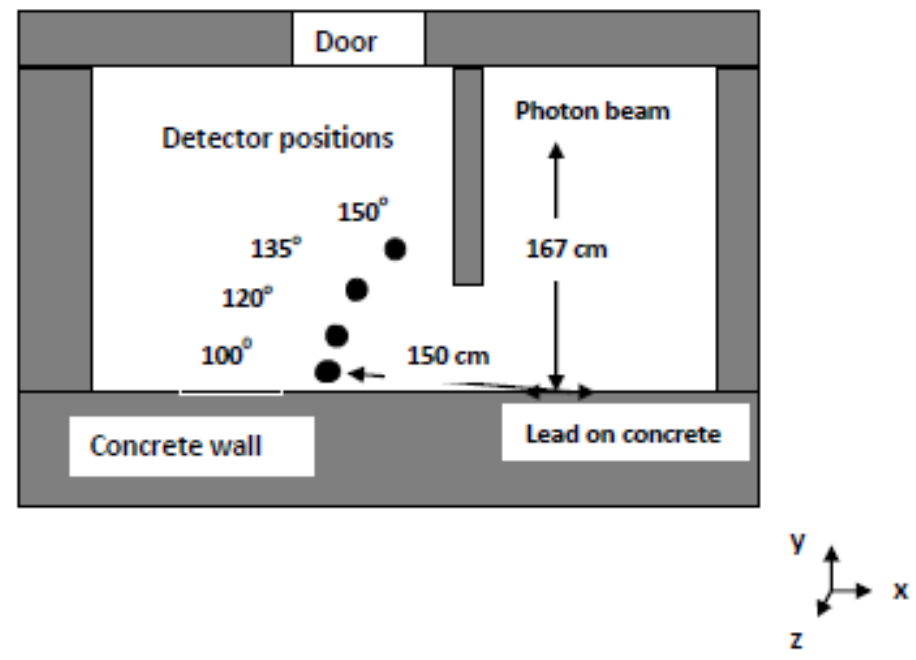

110 Figure 1a. Schematic diagram of the experiment (not to scale). Incident primary photon beam (solid arrows) on the concrete wall is perpendicular on the $\mathrm{x}$-axis. Detector was positioned at various angles (at $150 \mathrm{~cm}$ from the centre of the photon field at the wall) with respect with y-axis to measure the backscattered photons. Dashed arrows: scattered photons. Lead sheet of $1 \mathrm{~m}^{2}$ was placed on the concrete wall facing the photon beam. 
In the following sections several methods are described to measure the reduction in the dose of backscattered photons when lead was placed in front of the concrete wall compared to that of concrete alone. In addition, simulations of the measurements were

120 carried out using two Monte Carlo codes to confirm the measurements. Monoenergetic photons were used for the experiment and simulations in order to provide a better indication of the photon reflection as a function of photon energy. This is preferable to conducting the experiment in a RT room, where the Linear Accelerator x-ray spectrum is more complex. The leakage radiation from a Linear Accelerator is also appreciable and 125 would affect the measurement.

\section{EXPERIMENTAL METHOD AND MATERIALS}

130 All measurements were carried out at the laboratory of the Royal Scientific Society in Jordan. The schematic diagram of the experiment is shown in Fig. 1a. Two radiation sources were used for the measurements, Co-60 and Cs-137, both stored inside a shield. The sources were driven to the position of irradiation by remote control. The diameter of the aperture of the collimator for the source was $1 \mathrm{~cm}$. The height of the source from the

135 ground was $101 \mathrm{~cm}$. The room walls were made from concrete mixed with small iron pieces to reduce the photon transmission through the laboratory walls. The effective density of the concrete laboratory walls was not known. The source to wall distance was $167 \mathrm{~cm}$ and was incident on the concrete wall in the $-\mathrm{y}$ direction, parallel to the floor 
(Fig. 1a). The activities of the Co-60 and Cs-137 sources used were $13.107 \mathrm{GBq}$ and $140 \quad 1.587 \mathrm{TBq}$ respectively.

A few measurements were made to establish the width of the photon beam incident on the concrete wall. It was found that the irradiated area of the wall had a diameter of about 25 $\mathrm{cm}$, where beyond the dose rate was less than $10 \%$ of the dose rate at the centre of the

145 irradiated area, $D_{0}$. This arrangement ensured that the $1 \mathrm{~m}^{2}$ of lead used to cover the wall, facing the primary radiation, would include most of the incident beam.

However, the radiation leakage from the source head (Co-60 and Cs-137) contributed to a high level of background radiation which was greater than the dose from the backscattered photons, which were measured at a distance of $100 \mathrm{~cm}$ from the wall.

150 Therefore, the detector was moved back another $50 \mathrm{~cm}$ and placed at the side of a lead shield to reduce the leakage radiation dose (background) by about $75 \%$ (from $65 \mu \mathrm{R} / \mathrm{h}$ to $15 \mu \mathrm{R} / \mathrm{h}$ ). The detector used was a calibrated plastic scintillation counter (Portable Dose Ratemeter, Type PDR2-5V, Serial Number 823 by Nuclear Enterprises Ltd). The dose rate measured at $167 \mathrm{~cm}$ from the source, $D_{\mathrm{o}}$, for Co-60 was $103 \mathrm{mR} / \mathrm{h}$ and for Cs-137 155 was $1513 \mathrm{mR} / \mathrm{h}$.

The average background in the room at the points of measurement with the beam off was $15 \mu \mathrm{R} / \mathrm{h}$. The backscattered radiation was measured at a radius of $150 \mathrm{~cm}$ from the wall at angles of 100, 120, 135 and 150 degrees with respect to y-axis (Fig. 1a). These measurements were made for three situations; 1 - the radiation incident on the concrete 160 wall only, with a dose rate of $D_{c}, 2$ - the radiation incident on a $2 \mathrm{~mm}$ thickness of a 
square sheet made of lead $(100 \mathrm{~cm} \times 100 \mathrm{~cm})$ lining the concrete wall, with a dose rate of $D_{c l 2}$ and 3- the same as 2 but with a lead thickness of $4 \mathrm{~mm}$, and dose rate $D_{c l 4}$.

\section{MONTE CARLO SIMULATION}

FLUKA and EGS Monte Carlo codes were used to simulate the above experiments. FLUKA is a general-purpose particle interaction and transport code with roots in an extended range of applications starting from proton and electron accelerator shielding, to target design, radiotherapy, neutrino physics and many other areas. 5 EGS, initially

170 developed at SLAC, has been further developed for a range of applications with standard megavoltage x-ray beams, principally by the National Research Council (NRC) of Canada. ${ }^{10}$ For both codes the radiation source particle and its energy, the number of particles, the position of the beam, the materials, geometry, and their properties are defined in an input file. The whole system of the radiation source and geometry is

175 surrounded by a large region known as 'the void', which in the case of FLUKA is surrounded by a larger region known as the 'black-hole'. A black-hole has an infinite absorption cross-section and all particles disappear when they reach it.

An important feature of FLUKA is Flair, the Graphical User Interface (GUI), which is an advanced and user-friendly interface used to facilitate the editing of FLUKA input files,

180 execution of a code and visualisation of the output files. ${ }^{7}$ In Flair, everything is visually organised, and the user can freely create a code defining the simulation in any order they wish, such as modifications to the geometry. ${ }^{7}$ 
The computer configuration was a 32-bit Linux operating system (Mint 14) on an Intel quad-core (i5-2310) cpu running at $1.9 \mathrm{GHz}$.

\section{A. VALIDATION AND SIMULATION OF THE FLUKA CODE}

Calculation of the percentage depth-dose for a photon beam was simulated by FLUKA.

190 The results were compared with known and published experimental data in order to confirm the reliability of FLUKA in this energy range, as well as to check the effect of beam attenuators on the beam penetration properties of photons. For the depth-dose curve calculations, the geometry used in this simulation consists of a conical photon beam impinging on a rectangular parallelepiped water phantom. The photon beam had a radius

195 of $5.65 \mathrm{~cm}$ at the surface of the water phantom giving an equivalent area of $10 \times 10 \mathrm{~cm}^{2}$ at the phantom surface. The distance between the radiation source and phantom surface was $80 \mathrm{~cm}$ (for $1.25 \mathrm{MeV}$ photons from Co-60) and $100 \mathrm{~cm}$ for higher energies. The rectangular parallelepiped water phantom had a length $40 \mathrm{~cm}$ (facing the source), a width of $40 \mathrm{~cm}$, and a height of $40 \mathrm{~cm}$. A smaller concentric rectangular parallelepiped had a

200 length of $29.3 \mathrm{~cm}$ (parallel to the floor), a width of $4 \mathrm{~cm}$, and a height of $4 \mathrm{~cm}$ (perpendicular to the floor) was positioned inside the water phantom to define the dosescoring region. This smaller rectangular parallelepiped was divided into 31 slabs. The first slab was $0.3 \mathrm{~cm}$ thick and the second and third slabs were $0.5 \mathrm{~cm}$ thick respectively to demonstrate further details in the build-up region. These were followed by the 205 remaining 28 regions of $1.0 \mathrm{~cm}$ thickness positioned at the centre at each centimeter 
along the depth axis. The whole geometry was placed inside a sphere of radius $500 \mathrm{~cm}$ and of air medium and this was surrounded by a larger sphere of radius $5000 \mathrm{~cm}$ defined as a black-hole. Monoenergetic sources of $1.25 \mathrm{MeV}, 2.35 \mathrm{MeV}$, and $3.5 \mathrm{MeV}$ were representing the mean energies of Co-60 gamma-rays, and filtered $6 \mathrm{MV}$ and $10 \mathrm{MV} \mathrm{x}-$ 210 ray beams respectively. Simulations were performed for 5 cycles to calculate the standard deviation in order to obtain the required statistical uncertainty of $1-3 \%$. One million photon histories were followed for each simulation. The running time of the depth-dose calculations for Co-60, $6 \mathrm{MV}$, and $10 \mathrm{MV}$ was 2 hours for 5 independent simulations (cycles). The calculated percentage depth-dose agreed well with that published by the

215 British Journal of Radiology Supplement 25 (1996) ${ }^{8}$ for Co-60 and also corresponded to the internal data obtained from Singleton Hospital of $6 \mathrm{MV}$ and $10 \mathrm{MV}$ beam, within a $3 \%$ error for both codes.

The experimental condition in the above section was simulated as follows: a concrete 220 wall of $300 \times 300 \mathrm{~cm}^{2}$ was assumed to have a density of $2.34 \mathrm{~g} . \mathrm{cm}^{-3}$ and an elemental composition of $0.92 \%$ hydrogen, $49.83 \%$ oxygen, $1.71 \%$ sodium, $4.56 \%$ aluminum, $31.58 \%$ silicon, $1.92 \%$ potassium, $8.26 \%$ calcium and $1.22 \%$ iron (by weight). ${ }^{9}$ The thickness of the wall was assumed to be $50 \mathrm{~cm}$. The photon beam was collimated by selecting parallel and very small beam sizes $\left(0.1 \times 0.1 \mathrm{~cm}^{2}\right)$. A sheet of lead of density 22511.34 g.cm ${ }^{-3}$ and various thicknesses $(1 \mathrm{~mm}, 2 \mathrm{~mm}$, and $4 \mathrm{~mm})$ was simulated covering the concrete wall (facing the photon beam) to calculate the effect of adding lead to the wall. The whole geometry was placed inside a large sphere of $700 \mathrm{~cm}$ in radius and of air medium, which was then surrounded by a larger sphere defining the black-hole which 
was $7000 \mathrm{~cm}$ in radius (Fig. 1b). The backscattered photons were collected by a 230 parallelepiped of water with dimensions of $200 \mathrm{~cm}$ height (perpendicular to the floor) $\mathrm{x}$ $100 \mathrm{~cm}$ width (parallel to the floor) $\mathrm{x} 1 \mathrm{~cm}$ thickness. This large size was necessary to enhance the detector efficiency and reduce the computation time. The photon energy cut off was set to $10 \mathrm{keV}$ and the electron kinetic energy cut off was set to $10 \mathrm{keV}$ (the total energy cut off was $0.521 \mathrm{MeV}$ ). Rayleigh scattering was taken into account. 


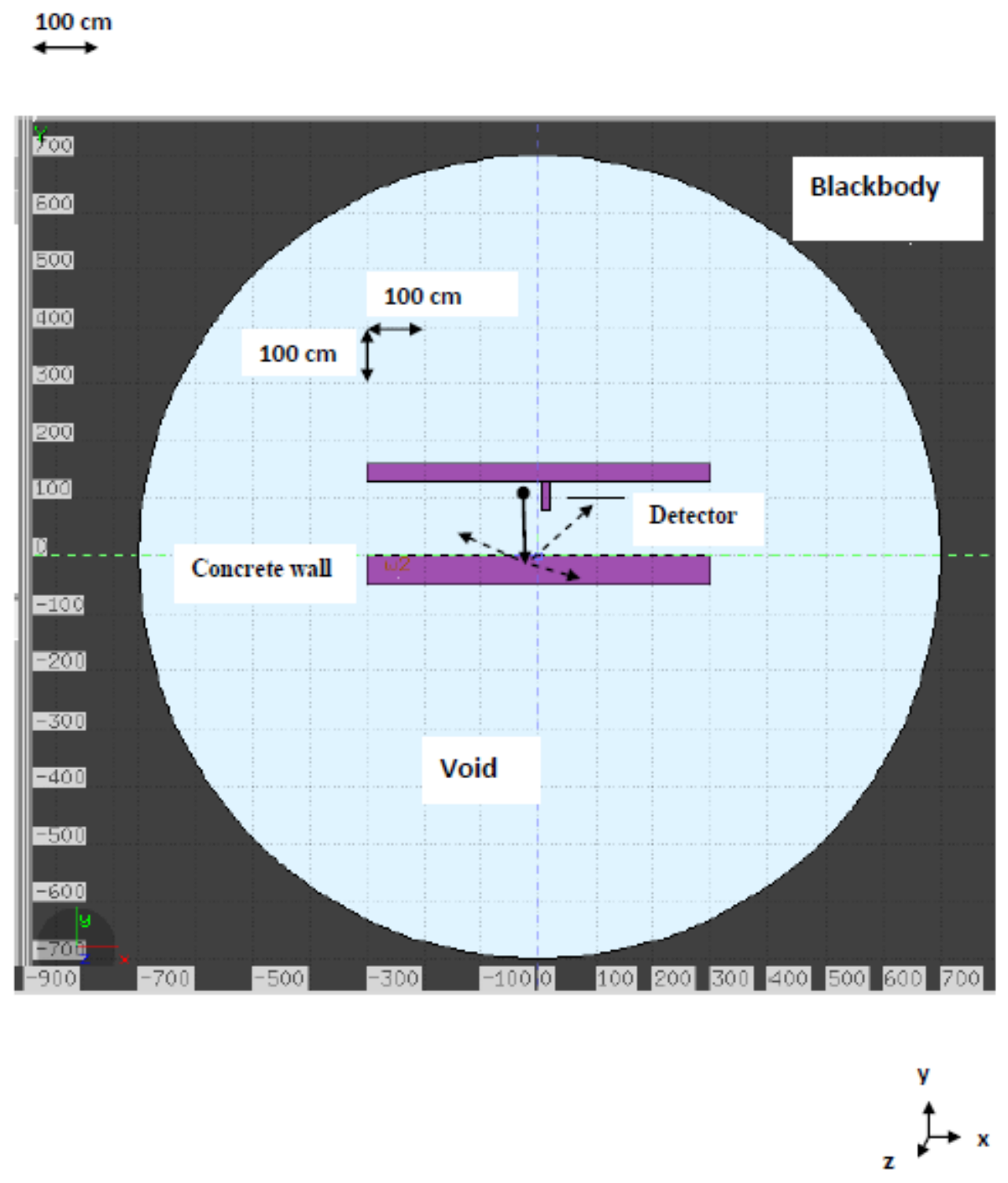

Figure 1b. Monte Carlo simulation of the above experiment as shown in Flair (the circle diameter is $1400 \mathrm{~cm}$ ). Photon beam (solid arrow) is incident from the $\mathrm{x}$-axis (i.e. in the -y 240 direction on the concrete wall perpendicular to the $\mathrm{y}$-axis). Detector is $100 \mathrm{~cm}$ in the $\mathrm{x}$ direction by $200 \mathrm{~cm}$ in the $\mathrm{z}$ direction and $1 \mathrm{~cm}$ in $\mathrm{y}$ direction. Scattered photons were represented by dashed lines. Void is filled with air. Area in black is black-hole. 


\section{B. VALIDATION AND SIMULATION OF THE EGS CODE}

The DOSXYZnrc user-code from the BEAMnrc package, which is based on the Monte Carlo code-base, EGS4, is a rectilinear geometry code used predominantly for phantom studies in radiation therapy. An equivalent geometry has been used to that of the FLUKA calculation (for the depth dose and backscattering dose calculations), with a voxel geometry employed instead of geometrical bodies. The ICRU defined composition of air was used, the concrete was chosen to be the same atomic composition as the FLUKA calculation. Similarly, the cutoff for photon transport was $10 \mathrm{keV}$ and the cutoff for electron transport was $0.521 \mathrm{MeV}$ (total).

\section{SIMULATION OF A RADIOTHERAPY ROOM AT SINGLETON HOSPITAL BY THE FLUKA CODE}

260 A typical RT room was simulated by the FLUKA code (as shown in Fig. 2). EGSnrc was not used to simulate the RT room because additional coding would have been required to model the complex geometry. The room walls, ceiling and floor were made of concrete of density $2.34 \mathrm{~g} . \mathrm{cm}^{-3}$. Also, in this simulation, the elemental composition of concrete was taken from $\mathrm{NCRP}^{9}$ as shown above. All walls had $100 \mathrm{~cm}$ thickness and both floor

265 and ceiling thicknesses were $50 \mathrm{~cm}$ (an assumption was used to speed up the computation 
without compromising the results). The maze walls and floor were lined with a $2 \mathrm{~mm}$ lead sheet of density $11.34 \mathrm{~g} . \mathrm{cm}^{-3}$. The photon source was fixed at $100 \mathrm{~cm}$ away from the surface of the rectangular parallelepiped water phantom that had a symmetric size of 40 $\mathrm{cm} \times 40 \mathrm{~cm} \times 40 \mathrm{~cm}$ along the beam axis. The reason for including a phantom was to 270 simulate the maximum dose at the maze entrance, as calculated by Al-Affan ${ }^{3}$ (i.e. the highest expected dose at the maze entrance). Although the photon source from the Linear Accelerator is divided into primary photons, scattered and leakage photons, in the present work the beam was assumed to have only primary photons and therefore leakage photons were not taken into account. The photon beam had a radius of $5.65 \mathrm{~cm}$ (at $100 \mathrm{~cm}$ from 275 the phantom surface) at the surface of water phantom giving an equivalent area of $10 \times 10$ $\mathrm{cm}^{2}$. 

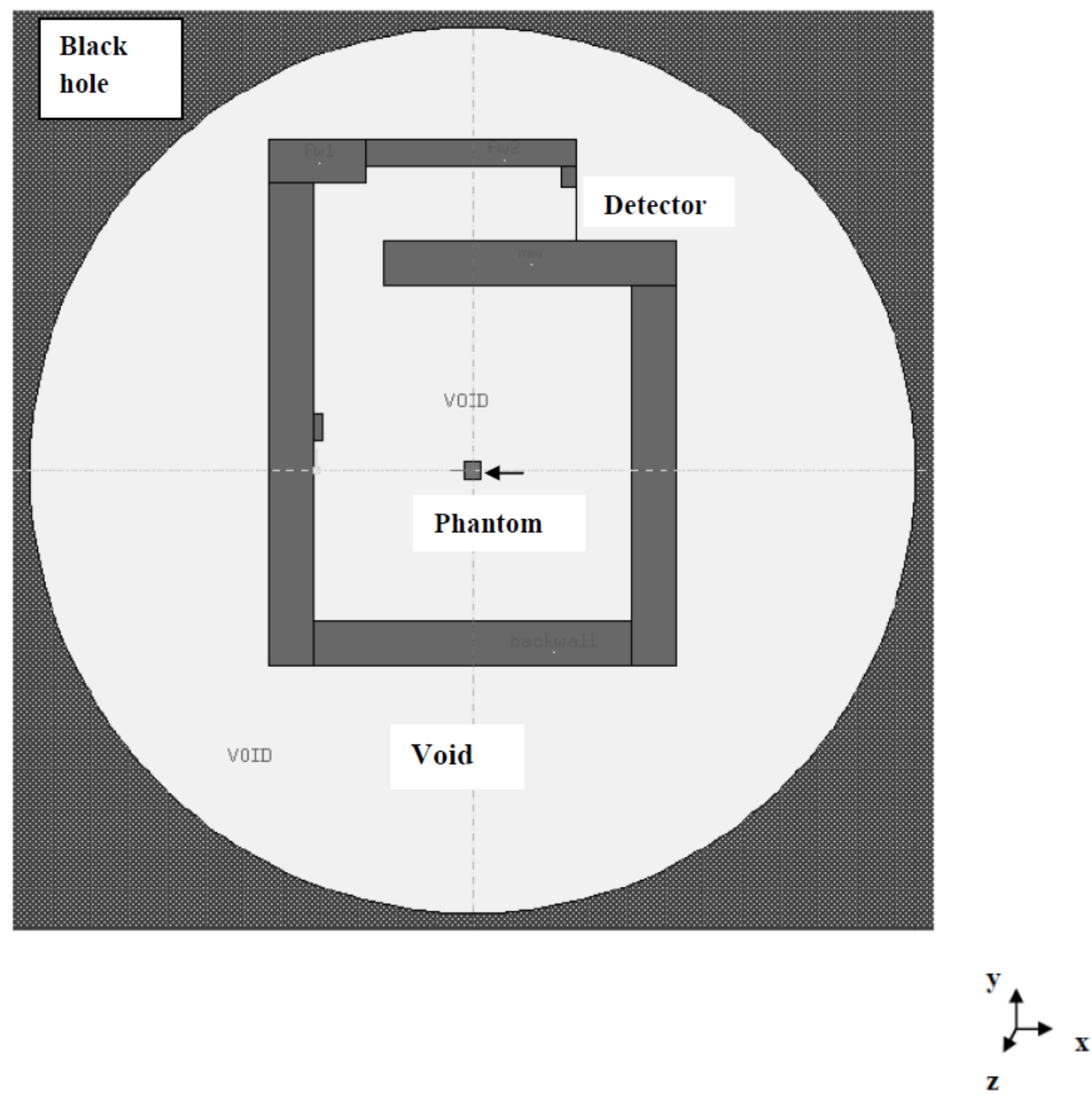

280 Figure 2. A FLUKA generated diagram of the radiotherapy room, which was used to calculate the dose for scattered photons at the maze entrance (the diameter of the white void region is $2000 \mathrm{~cm}$ ). The primary photon beam is in the $-\mathrm{x}$ direction. 
285 A large rectangular parallelepiped water detector was used to calculate doses of backscattered photons and positioned at the entrance of the maze and covered the maze as a door (Fig. 2). The detector was $120 \mathrm{~cm}$ in width in the y direction, $1 \mathrm{~cm}$ in depth in the $\mathrm{x}$ direction, and $200 \mathrm{~cm}$ in height in the $\mathrm{z}$ direction. The main advantages of using large detector were to increase its efficiency and reduce the computing time and statistical 290 error.

The whole geometry was surrounded by a large spherical void of a radius of $1000 \mathrm{~cm}$ consisting of air and this was surrounded by a black-hole region, with an outer sphere of a radius of $10000 \mathrm{~cm}$. The simulated irradiations were carried out for a range of photon 295 energies $(0.5,1,3,7$ and $10 \mathrm{MeV})$ to study several components of the $\mathrm{x}$-ray spectrum, which are usually present in the primary beam (of energies up to $10 \mathrm{MV}$ ). For each energy, the FLUKA code was run for 3 cycles to determine statistical fluctuations in the results. Moreover, 60 million photon histories were generated for each simulation to obtain a statistical uncertainty of better than $30 \%$. Computation time for the calculation of

300 the doses ranged from a few hours to about 35 hours with 3 cycles of the calculation for all situations. The transport cut-offs for photons and electrons (kinetic energy) were set to $10 \mathrm{keV}$ and $100 \mathrm{keV}$ respectively, to maintain a reasonable computation time and acceptable statistical error for this application. 


\section{EXPERIMENTAL RESULTS}

The measured dose rates are shown in Table I for Co-60 and Table II for Cs-137 for photon beams normally incident on the wall. Measured dose rates $D_{c}, D_{c l 2}$ and $D_{c l 4}$ are

310 shown as a function of the backscattered angle. However, when a $2 \mathrm{~mm}$ thick lead sheet was placed on the concrete wall the dose rate was reduced for all angles. The reduction 
Table I. The dose rate as a function of the reflecting angle for a Co- 60 beam incident 315 perpendicular on the concrete wall $\left(D_{c}\right)$ and also on the concrete wall lined with $2 \mathrm{~mm}$ $\left(D_{c 12}\right)$ and $4 \mathrm{~mm}$ lead $\left(D_{c 12}\right)$. The dose rate at reference is $D_{o}=103 \mathrm{mR} / \mathrm{h}$ is measured at a distance of $167 \mathrm{~cm}$ from the source. The background reading was $15 \mu \mathrm{R} / \mathrm{h}$. The data below shows the average measurement, minus the background reading.

\begin{tabular}{clccc}
320 & $\begin{array}{l}\text { Angle } \\
(\text { Degrees })\end{array}$ & $\begin{array}{l}\mathrm{D}_{\mathrm{c}}(\mu \mathrm{R} / \mathrm{h}) \\
\text { for concrete wall } \\
\text { only }\end{array}$ & $\begin{array}{l}\mathrm{D}_{\mathrm{cl} 2}(\mu \mathrm{R} / \mathrm{h}) \\
\text { for concrete wall } \\
\text { lined by } 2 \mathrm{~mm} \text { lead }\end{array}$ & $\begin{array}{l}\mathrm{D}_{\mathrm{cl} 4}(\mu \mathrm{R} / \mathrm{h}) \\
\text { for concrete wall } \\
\text { lined by } 4 \mathrm{~mm} \text { lead }\end{array}$ \\
325 & 134 & 131 & 130 \\
100 & 196 & 162 & 158 \\
120 & 211 & 172 & 170 \\
1350 & 258 & 213 & 210 \\
\hline \hline
\end{tabular}


335 Table II. The dose rate as a function of the reflecting angle for Cs-137 beam incident perpendicular on the concrete wall and also on the concrete wall lined with $2 \mathrm{~mm}$ and 4 $\mathrm{mm}$ lead. The dose rate at reference is $D_{\mathrm{o}}=1513 \mathrm{mR} / \mathrm{h}$ measured at a distance of $167 \mathrm{~cm}$ from the source. The background reading of $15 \mu \mathrm{R} / \mathrm{h}$ was subtracted from the readings below.

\begin{tabular}{llll}
\hline \hline $\begin{array}{l}\text { Angle } \\
\text { (Degrees) }\end{array}$ & $\begin{array}{l}\mathrm{D}_{\mathrm{c}}(\mu \mathrm{R} / \mathrm{h}) \\
\text { for concrete wall } \\
\text { only }\end{array}$ & $\begin{array}{l}\mathrm{D}_{\mathrm{cl} 2}(\mu \mathrm{R} / \mathrm{h}) \\
\text { for concrete wall } \\
\text { lined by 2 mm lead }\end{array}$ & $\begin{array}{l}\mathrm{D}_{\mathrm{cl} 4}(\mu \mathrm{R} / \mathrm{h}) \\
\text { for concrete wall } \\
\text { lined by } 4 \mathrm{~mm} \text { lead }\end{array}$ \\
100 & 613 & 240 & 240 \\
120 & 1256 & 347 & 318 \\
135 & 1443 & 389 & 348 \\
150 & 1668 & 484 & 423 \\
\hline \hline
\end{tabular}


355 was very small at an angle of 100 degrees. The reduction was about $20 \%$ for angles of 120 degrees and above for Co-60 and more than $70 \%$ for Cs-137. Also, above 120 degrees the ratio of reduction was nearly constant, as shown in Tables III and IV. It can also be noticed from Table I and Table II that when $4 \mathrm{~mm}$ lead was used, the dose rate was reduced by only a small amount more than $2 \mathrm{~mm}$. Therefore, $2 \mathrm{~mm}$ lead may be used

360 as the optimum thickness which would reduce the dose rate of the radiation reflected from the concrete wall for both Co-60 and Cs-137. It was found that the half value layer of lead was between 1 and $4 \mathrm{~mm}$ for photon energies of 150 and $400 \mathrm{keV}$, respectively. 
Table III. The ratio of the dose rate for the Co-60 beam incident perpendicular on the concrete lined with lead, to that of concrete.

\begin{tabular}{lll}
\hline \hline \multirow{2}{*}{$\begin{array}{l}\text { Angle } \\
\text { (Degrees) }\end{array}$} & $\begin{array}{l}\text { Ratio } \mathrm{D}_{\mathrm{cl} 2} / \mathrm{D}_{\mathrm{c}} \\
\text { for concrete wall } \\
\text { lined by 2 mm lead }\end{array}$ & $\begin{array}{l}\text { Ratio } \mathrm{D}_{\mathrm{cl} 4} / \mathrm{D}_{\mathrm{c}} \\
\text { for concrete wall } \\
\text { lined by 4 mm lead }\end{array}$ \\
\cline { 2 - 3 } 100 & 0.98 & 0.97 \\
375 & 0.83 & 0.81 \\
120 & 0.82 & 0.81 \\
135 & 0.83 & 0.81 \\
\hline \hline
\end{tabular}

380 
Table IV. The ratio of the dose rate for the Cs-137 beam incident perpendicular on the concrete lined with lead, to that of concrete.

385

\begin{tabular}{lll}
\hline \hline Angle & Ratio $\mathrm{D}_{\mathrm{cl} 2} / \mathrm{D}_{\mathrm{c}}$ & Ratio $\mathrm{D}_{\mathrm{cl} 4} / \mathrm{D}_{\mathrm{c}}$
\end{tabular}

(Degrees) for concrete wall for concrete wall

lined by $2 \mathrm{~mm}$ lead lined by $4 \mathrm{~mm}$ lead

390

$\begin{array}{lll}100 & 0.39 & 0.39 \\ 120 & 0.27 & 0.25\end{array}$

395

\begin{tabular}{lll}
135 & 0.27 & 0.24 \\
150 & 0.29 & 0.25 \\
\hline \hline
\end{tabular}


These energies are typical of backscattered photons for Co-60 and Cs-137 using the be different, as pair production will play an important role in reversing the dose reduction (Table VIII). Moreover, this finding has important implications for reducing the dose rate at the maze entrance of RT rooms if selected maze walls are lined by an appropriate thickness of lead, in effect trapping the backscattered photons. The data in Table I show the average of the measurements, minus the background reading.

The resulting estimated combined uncertainty was about $24 \%$. The above results consider the scattered spectrum of Co-60 and Cs-137 interacting with the plastic scintillator detector. The largest contribution to the uncertainty, due to the calibration and energy response of the instrument, will not affect the ratios determined; the interest was to study

410 the relative reduction in dose. The results were not corrected for changes in spectrum, but this effect is expected to be small in the energy range considered.

\section{FLUKA AND EGS MONTE CARLO RESULTS AND DISCUSSION}

415 The calculated doses of scattered photons from the wall are shown in Tables V to VIII for photon energies $0.25,0.662,1.25$ and $2 \mathrm{MeV}$, respectively, using the Monte Carlo codes FLUKA and EGS. It can be seen that there is a good agreement between the FLUKA and EGS calculations. The statistical error was between $2 \%$ and $8 \%$ for all calculations. 
The small error shows that both EGS and FLUKA can be used to simulate backscattering 420 photons of various energies by the concrete wall and also when a lead sheet is covering the wall. The ratio of the simulated dose by the FLUKA Code for a beam of Cs-137 incident perpendicular on the concrete lined with lead to that of concrete only is shown in Table VI. Table VII shows the calculations for Co-60. Total computing time for the calculations was between 2 and 45 minutes for each run. 
Table V. Comparison between FLUKA and EGS codes for backscattering photons from concrete wall with lead for a photon energy of $0.25 \mathrm{MeV}$. The source to wall distance was $101 \mathrm{~cm} .0 \mathrm{~mm}$ lead $=$ concrete only. Column 5 shows the ratio of dose when the concrete walls are covered with lead of various thicknesses to that of concrete only using 430 the FLUKA Code.

\begin{tabular}{|c|c|c|c|c|}
\hline $\begin{array}{l}\text { Lead } \\
\mathrm{mm}\end{array}$ & $\begin{array}{l}\text { FLUKA dose } \\
\text { Gy/photon }\end{array}$ & $\begin{array}{l}\text { EGS dose } \\
\text { Gy/photon }\end{array}$ & EGS/FLUKA & $\begin{array}{l}\text { FLUKA } \\
\text { Dose ratio } \\
\mathrm{d}_{\mathrm{Cl}} / \mathrm{d}_{\mathrm{C}}\end{array}$ \\
\hline 0 & $1.43 \mathrm{E}-18 \pm 2 \%$ & $1.39 \mathrm{E}-18 \pm 1.6 \%$ & 0.97 & 1 \\
\hline 1 & $2.15 \mathrm{E}-19 \pm 9 \%$ & $1.88 \mathrm{E}-19 \pm 4 \%$ & 0.87 & 0.15 \\
\hline 2 & $2.1 \mathrm{E}-19 \pm 1.5 \%$ & $1.82 \mathrm{E}-19 \pm 4 \%$ & 0.87 & 0.15 \\
\hline 4 & $2.06 \mathrm{E}-19 \pm 7 \%$ & $1.91 \mathrm{E}-19 \pm 4.2 \%$ & 0.93 & 0.14 \\
\hline
\end{tabular}


Table VI. Comparison between the FLUKA and EGS codes for backscattering photons 435 from concrete wall with lead. Photon energy: $0.662 \mathrm{MeV}$ (Cs-137). Photon cutoff energy: $10 \mathrm{keV}$. Also, column 5 shows the ratio of dose when the concrete walls are covered with lead of various thicknesses to that of concrete only using the FLUKA Code.

\begin{tabular}{|c|c|c|c|c|}
\hline $\begin{array}{l}\overline{\text { Lead }} \\
\mathrm{mm}\end{array}$ & $\begin{array}{l}\text { FLUKA dose } \\
\text { Gy/photon }\end{array}$ & $\begin{array}{l}\text { EGS dose } \\
\text { Gy/photon }\end{array}$ & EGS/FLUKA & $\begin{array}{c}\text { FLUKA } \\
\text { Dose Ratio } \\
\mathrm{d}_{\mathrm{Cl}} / \mathrm{d}_{\mathrm{C}}\end{array}$ \\
\hline 0 & $1.91 \mathrm{E}-18 \pm 3.2 \%$ & $1.81 \mathrm{E}-18 \pm 1.8 \%$ & 0.95 & 1 \\
\hline 1 & $5.01 \mathrm{E}-19 \pm 2.6 \%$ & $4.81 \mathrm{E}-19 \pm 3.6 \%$ & 0.96 & 0.26 \\
\hline 2 & $2.70 \mathrm{E}-19 \pm 2.3 \%$ & $2.58 \mathrm{E}-19 \pm 5.3 \%$ & 0.95 & 0.14 \\
\hline 4 & $2.01 \mathrm{E}-19 \pm 1.3 \%$ & $1.90 \mathrm{E}-19 \pm 6.1 \%$ & 0.95 & 0.11 \\
\hline
\end{tabular}

440 
Table VII. Comparison between the FLUKA and EGS codes for backscattering photons from concrete wall with lead. Photon energy: $1.25 \mathrm{MeV}$ (Co-60). Photon cutoff energy: $10 \mathrm{keV}$. Also, column 5 shows the ratio of dose when the concrete walls are covered with 445 lead of various thicknesses to that of concrete only using the FLUKA Code.

\begin{tabular}{lllll}
\hline \hline $\begin{array}{l}\text { Lead } \\
\mathrm{mm}\end{array}$ & $\begin{array}{l}\text { FLUKA dose } \\
\text { Gy/photon }\end{array}$ & $\begin{array}{l}\text { EGS dose } \\
\text { Gy/photon }\end{array}$ & EGS/FLUKA & $\begin{array}{l}\text { FLUKA } \\
\text { Dose Ratio } \\
\mathrm{d}_{\mathrm{C}} / \mathrm{d}_{\mathrm{C}}\end{array}$ \\
\hline 0 & $1.76 \mathrm{E}-18 \pm 5.4 \%$ & $1.65 \mathrm{E}-18 \pm 2.1 \%$ & 0.94 & 1 \\
1 & $1.14 \mathrm{E}-18 \pm 6.4 \%$ & $1.13 \mathrm{E}-18 \pm 4.3 \%$ & 0.99 & 0.65 \\
2 & $8.32 \mathrm{E}-19 \pm 2.9 \%$ & $8.20 \mathrm{E}-19 \pm 5.5 \%$ & 0.99 & 0.47 \\
4 & $7.91 \mathrm{E}-19 \pm 8.7 \%$ & $7.20 \mathrm{E}-19 \pm 6.3 \%$ & 0.91 & 0.45 \\
\hline \hline
\end{tabular}


Table VIII. Comparison between the FLUKA and EGS codes for backscattering photons 450 from concrete wall with lead. Photon energy: $2 \mathrm{MeV}$. Photon cutoff energy: $10 \mathrm{keV}$. Also, column 5 shows the ratio of dose when the concrete walls are covered with lead of various thicknesses to that of concrete only using the FLUKA Code.

\begin{tabular}{lllll}
\hline \hline $\begin{array}{l}\text { Lead } \\
\mathrm{mm}\end{array}$ & $\begin{array}{l}\text { FLUKA dose } \\
\text { Gy/photon }\end{array}$ & $\begin{array}{l}\text { EGS dose } \\
\text { Gy/photon }\end{array}$ & EGS/FLUKA & $\begin{array}{l}\text { FLUKA } \\
\text { Dose Ratio } \\
\mathrm{d}_{\mathrm{Cl}} / \mathrm{d}_{\mathrm{C}}\end{array}$ \\
\hline 0 & $1.82 \mathrm{E}-18 \pm 4 \%$ & $1.6 \mathrm{E}-18 \pm 2.4 \%$ & 0.88 & 1 \\
1 & $2.2 \mathrm{E}-18 \pm 6.1 \%$ & $2.34 \mathrm{E}-18 \pm 4.5 \%$ & 1.06 & 1.21 \\
2 & $2.0 \mathrm{E}-18 \pm 2 \%$ & $2.13 \mathrm{E}-18 \pm 4.9 \%$ & 1.07 & 1.10 \\
4 & $1.89 \mathrm{E}-18 \pm 2.8 \%$ & $2.12 \mathrm{E}-18 \pm 5.0 \%$ & 1.12 & 1.04 \\
\hline \hline
\end{tabular}


Table IX. Calculations of dose and \%DRF at the maze entrance using the FLUKA code for scattering photons from concrete wall with $2 \mathrm{~mm}$ lead (for a situation of 4 walls and a floor). $10 X 10 \mathrm{~cm}^{2}$. Lintel height $=220 \mathrm{~cm}$. Width $=160 \mathrm{~cm}$.

460

\begin{tabular}{llllc}
\hline \hline $\begin{array}{l}\text { Photon Energy } \\
\text { MeV }\end{array}$ & $\begin{array}{l}\text { FLUKA dose } \\
\mathrm{D}_{\mathrm{c}} \\
\text { Gy/photon }\end{array}$ & $\begin{array}{l}\text { FLUKA dose } \\
\mathrm{D}_{\mathrm{c} 2} \text { Gy/photon }\end{array}$ & $\begin{array}{l}\text { Ratio= } \\
\mathrm{D}_{\mathrm{c} 12} / \mathrm{D}_{\mathrm{c}}\end{array}$ & \% DRF \\
\hline 0.5 & $6.83 \mathrm{E}-22 \pm 12 \%$ & $4.61 \mathrm{E}-23 \pm 23 \%$ & 0.07 & 93 \\
1 & $1.11 \mathrm{E}-21 \pm 12 \%$ & $8.00 \mathrm{E}-23 \pm 27 \%$ & 0.07 & 93 \\
3 & $1.27 \mathrm{E}-21 \pm 18 \%$ & $1.2 \mathrm{E}-22 \pm 27 \%$ & 0.1 & 90 \\
7 & $1.37 \mathrm{E}-21 \pm 9 \%$ & $4.98 \mathrm{E}-22 \pm 36 \%$ & 0.36 & 64 \\
10 & $1.53 \mathrm{E}-21 \pm 6 \%$ & $1.47 \mathrm{E}-21 \pm 13 \%$ & 0.96 & 4 \\
\hline \hline
\end{tabular}


It can be seen from Tables V and VIII that introducing lead sheets of various thicknesses in the simulation reduced the dose of the scattered photons by a factor of between $50 \%$ and $80 \%$ for Co-60 and $70 \%$ to about $90 \%$ for Cs-137. This was a higher reduction of dose than the measurements that were recorded and the main reason for this is expected to be due to the higher attenuation of the concrete due to the presence of iron in the measurements. In addition only $1 \mathrm{~m}^{2}$ of the concrete walls was covered by lead compared 470 to all of the wall area being covered by lead in the Monte Carlo simulation. Again, the most optimal thickness was $2 \mathrm{~mm}$ where a reduction in the dose was achieved of about $53 \%$ for Co-60 and $85 \%$ for Cs-137. This is interesting since it shows that although the reduction was higher for the FLUKA simulation, there is an appreciable improvement when the energy of the photon was reduced from Co-60 to Cs-137 (column 5 in the

475 Tables). The reason for the trend is that the photoelectric effect for lead is effective up to about $1 \mathrm{MeV}$ and increasingly dominant below that energy; hence more greatly attenuating scattered photons of lower energies.

Above $1.02 \mathrm{MeV}$ pair production begins to contribute and will increase with increasing 480 photon energy. The pair production contributions to the total cross section in lead at energies $1,1.5,2,5,10 \mathrm{MeV}$ are $0,3.2,10.9,50$ and $73 \%$ respectively. ${ }^{11}$ Also the photoelectric effect will decrease with increasing photon energy and will be negligible compared to the pair production (the ratio of PE to pair production cross sections in lead dropping from 4.8 to 0.015 in the energy interval 1.5 to $10 \mathrm{MeV}) .{ }^{11}$ The result is the 485 emission of electron-positron pairs, and subsequent annihilation to produce photons 
travelling in all directions including towards the dosemeter. The process enhances the dose of the backscattering photons and increases the total dose as shown in Table VIII for $2 \mathrm{MeV}$ photons. Therefore above $2 \mathrm{MeV}$ using a lead sheet to cover the concrete wall would enhance the dose of the backscattering photons and would not be useful. For this

490 reason, careful thought is required about where to place lead in the RT rooms to achieve maximum scattered photon absorption and hence dose reduction at the maze entrance. 
There are a few differences between the experimental set up and the FLUKA and EGS simulation. The first is that the amount of iron in the concrete compound is not the same. The amount of iron in the wall is higher than that in the simulation, as the concrete wall at 495 the Royal Scientific Society had small pieces of iron mixed with the concrete to enhance the photon absorption and keep the wall thickness optimum. The second factor is that the photon beam emitted from the Co-60 and Cs-137 had been collimated, which in turn scattered some of the beam in all directions, whilst the beam from FLUKA was narrow, parallel and monoenergetic. The third factor was that the lead only covered $1 \mathrm{~m}^{2}$ of the concrete wall, not the whole wall as simulated by FLUKA and EGS. Another factor was the fluctuation in the dose rate reading and the dosemeter response as a function of the photon energy. However, it is clear that adding between 1 and $4 \mathrm{~mm}$ of lead to the concrete wall will significantly reduce the backscattered photons. This should have a direct implication for the design of mazes for RT rooms.

Table IX shows that the ratio of the dose at the maze entrance when $2 \mathrm{~mm}$ lead was used, compared to that with no lead (only concrete wall), varies from 0.07 to about 0.96 , depending on the energy of the primary beam. Therefore, it is necessary to know the spectrum of the primary beam to be able to simulate the dose calculations at the maze

510 entrance. However, for photon energies of up to $3 \mathrm{MeV}$ there is little variation, with an average ratio of about 0.1 . This study shows that using a $2 \mathrm{~mm}$ lead lining in the maze could reduce the dose scattered through the maze by about $90 \%$. 
It is useful in this study to introduce the concept of Dose Reduction Factor (DRF), the amount of reduction in photon dose at the maze entrance when lead is covering the maze 515 concrete walls (Table IX column 5).

Dose Reduction Factor can be represented by the equation $\mathrm{DRF}=1-\left(\mathrm{d}_{\mathrm{c}} / \mathrm{d}_{\mathrm{c}}\right)$. Tables IX shows the percentage DRF for lead thickness of $2 \mathrm{~mm}$ and various photon energies. Therefore, the DRF is about $90 \%$ for primary photons below $3 \mathrm{MeV}$ and up to $64 \%$ for energies between 3 and $7 \mathrm{MeV}$, which can be effective for most of the components in the

$52010 \mathrm{MV}$ spectrum. In an earlier study Baker and Thomas ${ }^{12}$ showed that cladding the maze concrete walls with either wood, polyethylene or a commercially available plastic, resulted in a reduction of the neutron dose by about $40 \%$ and photon dose by $10 \%$ at the maze entrance. Wang et al ${ }^{13}$ have studied the change of the neutron and photons dose rate at the maze entrance during the upgrading of the RT room from $6 \mathrm{MV}$-rays to 18

$525 \mathrm{MV}$. They found that cladding the maze concrete wall with a thickness of $2.5 \mathrm{~cm}$ borated polyethylene boards reduced the measured dose of neutrons and photons at the maze entrance by $41 \%$ and $59 \%$, respectively. This method was found to be more economical and feasible than increasing the door thickness, by mainly reducing the capture gamma dose arising from neutron-capture induced gamma emission. Low Z borated polyethylene 530 boards were used to reduce the neutron dose and consequently the photon dose was reduced.

\section{CONCLUSIONS}


535 This study shows that a few millimeters of a suitable high atomic number element such as lead could be used to cover the maze walls to reduce the photon dose rate at the RT room maze entrance by as much as $90 \%$, depending on the maze shape and photon spectrum reaching the maze entrance. This is due to the effect of the photoelectric interaction on scattered photons, which is proportional to the $\mathrm{Z}^{3}$ of the materials used. Covering part or

540 all of the maze walls with lead may be cost effective, especially in situations where extending the maze length or changing its shape would not be possible because of space restriction. This would be particularly useful in the case of upgrading the RT room use, e.g. from Co-60 to x-rays from Linear Accelerators of a higher energy. FLUKA has shown to be a useful tool to simulate different complex scenarios to predict such results

545 in advance of construction. In fact, Monte Carlo simulations can also be extremely useful in guiding the design of a new RT room. ${ }^{14}$

It should also be noted that this proposal would be viable only when the dose rate from leakage photons to the maze entrance is not dominant compared to that from the scattered photons throughout the maze, since the spectrum reaching the maze entrance due to the 550 leakage has high energy photon components. ${ }^{3}$ This novel technique could be developed further to include certain materials that absorb neutrons which may be present in the maze for Linear Accelerators of high energy x-rays. In general, with these methods, it may be possible to avoid the use of doors in future RT room design. More studies are required to simulate the various scenarios that may occur, including the presence of 555 leakage. Further measurements are also required to confirm the estimated DRF calculated with Monte Carlo simulations. 


\section{REFERENCES}

560 1P.H. McGinley and J.L. James, "Maze design methods for 6- and 10-MeV accelerators," Rad. Prot. Manage. 14 59-64 (1997).

${ }^{2}$ I.A.M. Al-Affan, C.W. Smith, H.M. Morgan and S.C. Llillicrap, "Dose rate and energy distributions of X-rays from a linear accelerator at the maze entrance of a radiotherapy room by measurement and Monte Carlo Simulation,” Radiat. Prot. Dosim. 78 273-277 565 (1998).

${ }^{3}$ I.A.M. Al-Affan, "Estimation of the dose at the maze entrance for $\mathrm{x}$-rays from radiotherapy linear accelerator,” Medical Physics, 27 231-238 (2000).

${ }^{4}$ P.J. Biggs, "Calculation of shielding door thicknesses for radiation therapy facilities using the ITS Monte Carlo Program,” Health Physics 61 465-472 (1991).

$570{ }^{5}$ G. Battistoni, F. Broggi, M. Brugger, M. Campanella, M. Carboni, A. Emple, A. Fasso, E. Gadioli, F. Cerutti, A. Ferrari, M. garzelli, M. Lantz, A. Mairani, M. Margiotta, C. Moroni, S. Muraro, K. Parodi, V. Patera, M. Pelliccioni, L. Pinsky, J. Ranft, S. Rpesler, S. Rollet, P. Sala, M. Santana, L. Sarchiapone, M. Sioli, G. Smirnov, F. Sommerer, C. Theis, S. Trovati, R. Villari, H. Vincke, V. Vlachoudis, J. Vollaire, and N. Zapp, "The

575 application of the Monte Carlo Code FLUKA in radiation protection studies for the large hadron collider," Progress in Nuclear Science and Technology, 2 358-364 (2011).

${ }^{6}$ A. Ferrari, P. Sala, A. Fasso, and J. Ranft, "Fluka: a multi-particle transport code" [Online]. Available at: http://www.fluka.org/content/manuals/FM.pdf (2011). 
${ }^{7}$ V. Vlachoudis, "Flair: A powerful but user friendly graphical interface for FLUKA," 580 International conference on Mathematics, Computational Methods and Reactor Physics, New York: American Nuclear Society, (2009).

${ }^{8}$ British Journal of Radiology Supplement 25, "Central axis depth dose data for use in radiotherapy," London: British Institute of Radiology, (1996).

${ }^{9}$ NCRP, “Structural Shielding Design and Evaluation for Megavoltage X- and Gamma585 Ray Radiotherapy Facilities,” NCRP Report 151 71-73 (2005).

${ }^{10}$ I. Kawrakow and B. R. B. Walters, "Efficient photon beam dose calculations using DOSXYZnrc with BEAMnrc," Med. Phys. 33, 3046-3056, (2006).

${ }^{11}$ J. Hubble, “ Photon Cross Sections, attenuation coefficients and energy absorption coefficients from $10 \mathrm{keV}$ to $100 \mathrm{GeV}$," (Table 3-22) NSRDS-NBS 29, National Standard 590 Reference Data Series, National Bureau of Standard (1969).

${ }^{12}$ C.R. Baker and S.J. Thomas, "Neutron transport in a clinical linear accelerator bunker: Comparison of materials for reducing the photo-neutron dose at the maze entrance," Radiation Physics and Chemistry, 61 Issue 3-6, 633-634 (2001). ${ }^{13}$ X. Wang, C. Esquivel, E. Nes, C. Shi, N. Papanikolaou, M. Charlton, "The neutron 595 dose equivalent evaluation and shielding at the maze entrance of a Varian Clinac 23EX treatment room,” Medical Physics 38, Issue 3, 1141-1149 (2011).

${ }^{14}$ C.W. Smith, I.A.M. Al-Affan and S. Green, "The use of Computer Programs in Treatment Room Design," Chapter 7 in IPEM Publications entitled " The design of Radiotherapy Treatment Room Facilities’, Eds: B. Stedeford, H.M. Morgan and W.P.M. 600 Mayles, The Institute of Physics and Engineering in Medicine, IPEM Report 75, York (1997). 